\title{
SDR-WBFM Receiver as an alternative to replace equipment in FM extended
}

Ramon Mayor Martins 


\title{
SDR-WBFM Receiver as an alternative to replace equipment in FM extended
}

\author{
Ramon Mayor Martins
}

\begin{abstract}
A presidential decree in Brazil authorizing the migration of AM broadcast to FM. To accommodate these stations, the FM band will receive the frequencies of the channels 5 and 6 of analog TV, which became known as "FM extended". One of the barriers found in migration is the acquisition of equipment by the users, as the current equipment does not have the expected range in FM extended. To mitigate this problem, the implementation of an $F M$ receiver using the Software Defined Radio (SDR) for its flexibility is proposed. The receiver was developed in GNU Radio environment, with a simple programming was possible to create a low-cost receiver and can serve as an alternative to users for receiving the new band.
\end{abstract}

Index Terms-Broadcast, migration, receiver, Software Defined Radio.

\section{INTRODUCTION}

$I^{2}$ Brazil, the presidential decree 8139/2013 [1] authorizes the migration of radio stations operating in the AM band $(525 \mathrm{kHz}$ a $1705 \mathrm{kHz}$ ) [2] to the FM band. The rules were set by the Ministry of Communications in the order 127 of 12 March 2014 [3]. Currently exist in Brazil 1,781 AM radio stations, of this total, 1,386 have asked to move to the FM band [4]. Channels 5 and 6, which are now occupied by analog TV channels will be vacated and intended for FM stations to accommodate migrate [5]. Today, the FMs are tuned in the range of $87.9 \mathrm{MHz}$ to $107.9 \mathrm{MHz}$. With the release of channels, this frequency will be extended from 76 $\mathrm{MHz}$ to $107.9 \mathrm{MHz}$. One of the issues for broadcasters is in changing the infrastructure to suit this new range, known as "FM extended", and one of the impasses for users is to purchase new equipment that have the FM band starting at 76 $\mathrm{MHz}$, today most equipment such as vehicular radios, portable radios, radios in smartphones, among others start at 87.9 MHz. The concept of Software-defined radio (SDR) allows replace the traditional implementation of hardware communication devices for a more flexible implementation that makes use of programmable devices controlled by software, such as a personal computer or an embedded processor [6].

Reconfigurable radio technologies provides an opportunity to reduce infrastructure costs, provide more efficient wireless connectivity across various networks, and offer a new dimension of operational flexibility that can ultimately enhance network performance [7].

SDR has emerged as a revolutionary approach to developing and operating communication radios for a broad range of domains including commercial, military, and public service. Advances in digital signal processing and computing power have enabled the evolution of radio implementations from primarily electronically (i.e., hardware) based to firmware and/or software-based. Each of these application domains has leveraged reconfigurable hardware to satisfy the specific desired operating requirements [8].

The purpose of this letter is to use the SDR inexpensive device to implement WBFM (wideband FM) receiver as an alternative to replace the equipment in AM- FM migration, this implementation will be use the GNU Radio environment.

In the second section will be presented the features and architecture of an SDR. In the third section will present the GNU Radio environment and the implementation of the receiver WBFM. Finally it will be completed on resources.

\section{SofTWARE DEFINED RADIO AND GNU RADIO ENVIRONMENT}

Wireless Innovation Forum defined SDR as "radio in which some or all of the functions of the physical layer are defined by software", in other words SDR refers to technology which software modules are executed in real-time generic platforms microprocessors, digital signal processors or programmable logic circuitry to implement functions the signal to be transmitted generation (modulation) or detection of the received radio signal (demodulation) [6].

SDR technology has emerged as a solution for prototyping wireless transceivers and networks by taking advantage of its customizable features to accelerate development time. As a result, a growing number of applications, such as national defense, public safety, connected vehicles, and education, can benefit from SDR technology [7].

The SDR technology may be employed in several radio frequency applications, such as Bluetooth, WLAN, GPS, Radar, WiMAX, LTE, etc. A SDR is nothing more than a communication system software-based, the main characteristics of operation can be modified at run time: the system can be easily re-configured to perform different functions according to need [6].

\section{A. SDR Architecture}

SDR technology implements radio functionalities like modulation/demodulation, signal generation, signal processing and signal coding in software instead of hardware as in conventional radio systems. The software implementation provides a higher degree of flexibility and reconfigurability and many benefits including the capability to change the channel assignments, to change the provided communication services or modify the transmission parameters or communication protocols [9]. The SDR 
operates as follows, as can be seen in Figure 1.

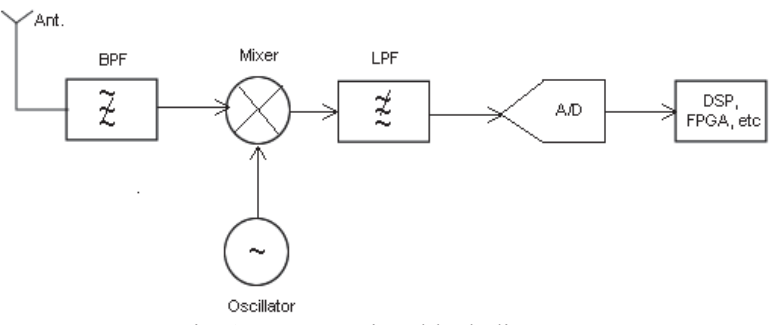

Fig. 1. SDR receiver block diagram.

As explain [10] low-noise amplifier is placed immediately after an antenna or filter, followed by a block of intermediate frequency (IF), this block deals with downconversion and translating the frequency of interest into a generic IF. Moreover, some filters could be inserted in this block to reduce the bandwidth of interest in a range that agrees with the next block of sampling/generation (in order to satisfy the Nyquist theorem). An analog-to-digital converter (ADC) fixes the range of frequency within which the SDR will work. After the conversion block, signal samples can be processed by a processing unit (i.e. a digital signal processor (DSP), a field-programmable gate array (FPGA), or personal computer (PC), giving extreme flexibility to the system.

For the development of reconfigurable SDR application was used for the experiment the GNU Radio environment.

\section{B. GNU Radio}

GNU Radio is a free software toolkit licensed under the GPL for implementing SDR. Initially, it was mainly used by amateur radio enthusiasts, but it later gained significant interest from wireless researchers, and today it has a large community of users and contributors [7]. The GNU Radio provides a development environment and note processing to implement SDR [6]. Several software algorithms include filters, channel codes, synchronization elements, equalizers, demodulators, decoders, and many other elements. It's possible to use these components as building blocks of a communication system [7].

The applications were developed using GNU Radio the Python programming language, which were built connections between the processing units. The block itself, they were developed in $\mathrm{C}++$ for performance reasons [6]. With the set of blocks already provided by GNU Radio, a large number of applications can be resolved without need to create specific blocks, which makes the faster and easier development.

\section{RECEIVER SYSTEM WBFM FOR FM EXTENDED}

Application possibilities are huge when using a low-cost SDR device and a programming environment such as GNU Radio. In this sense it's possible to create and manage a FM receiver system for extend FM bands from $76 \mathrm{MHz}$ to 107.9 . It's even possible to develop a robust system using filters, gain setting, bandwidth control, and other improvements in software, giving to the user the possibility to customize their system.

Initially it used the "RTL-SDR Source" block, this block will collect the signals in a range of $2.88 \mathrm{MHz}$ received from the dongle, this is also adjusted the reception gains to $30 \mathrm{~dB}$ and frequency with a variable called "freq". That variable has a band ranging from $76 \mathrm{MHz}$ to $107.9 \mathrm{MHz}$, it's possible to scan steps of 200. This value is the bandwidth that a commercial FM station occupies according to the Carson's bandwidth rules, which takes into account the frequency offset of $75 \mathrm{kHz}$ and a maximum frequency modulating of 15 $\mathrm{kHz}$.

After these adjustments, the data flow is directed to block "Low Pass Filter (LPF)", that block will filter the total signal of $200 \mathrm{kHz}$ for $100 \mathrm{kHz}$ cutoff frequency, and a transition band of $10 \mathrm{kHz}$, which concentrates information stereo FM signal. An stereo FM signal has the following composition as in Figure 2 below.

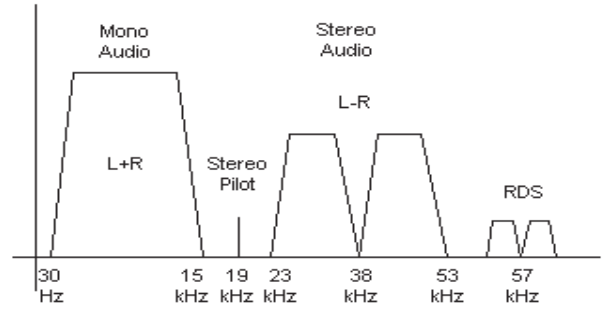

Fig. 2. Stereo FM Spectrum.

In this LPF block is also performed a decimation, according Nyquist enough to the $200 \mathrm{kHz}$ of the stations. After this treatment the way, is included a block "WBFM Receiver". This block is responsible for the demodulation of the FM signal itself. An important issue in this block is the audio decimation to suit the device's sound card where it's implementing in our case $48 \mathrm{kHz}$.

The next step is the inclusion of a deemphasis with FM "deemphasis block", this block is necessary because the noise has a greater effect at higher modulating frequency than the lower, accordingly, the transmission is performed a preemphasis in high frequencies (i.e., the higher frequencies are artificially enhanced or reinforced at the transmitter to provide greater noise immunity), and reception takes place a deemphasis.

After deemphasis, another filter is included, optional, to remove the carrier from $15 \mathrm{kHz}$, to simplify reception, in this case, would be received only the "L + R" FM spectrum portion. In the final step, is included "Multiply Const" block with a variable call volume to adjust the intensity of the audio and finally, is included a block called "Audio Sink", which will allow the signal conversion for proper audio to sound card computer.

The system screen in GNU Radio with blocks can be seen in Figure 3, the spectrographic screen and the waterfall can be seen in Figure 4. 


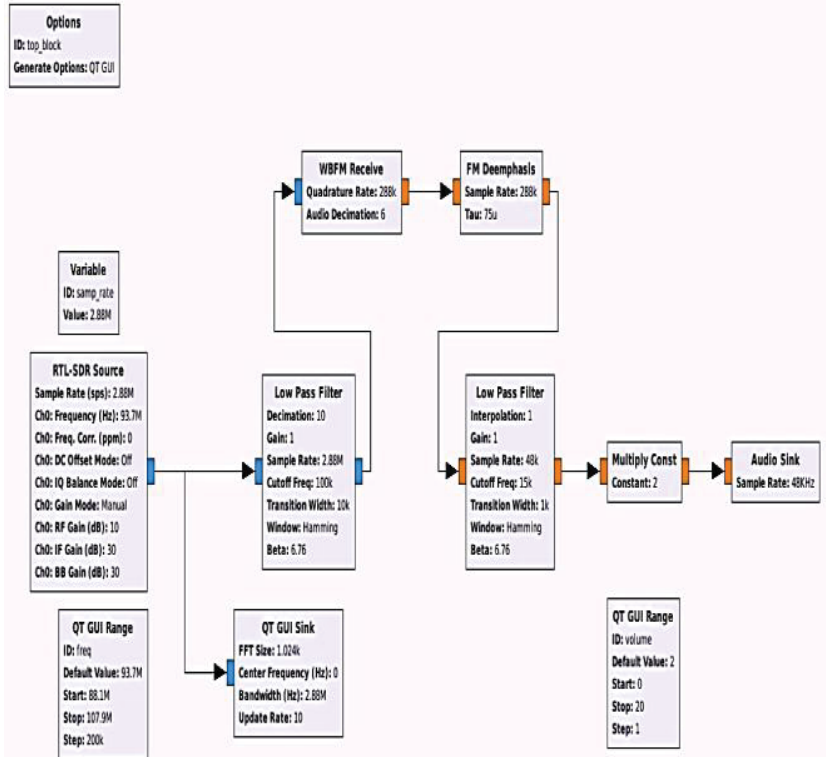

Fig. 3. WBFM receiver in GNU Radio environment

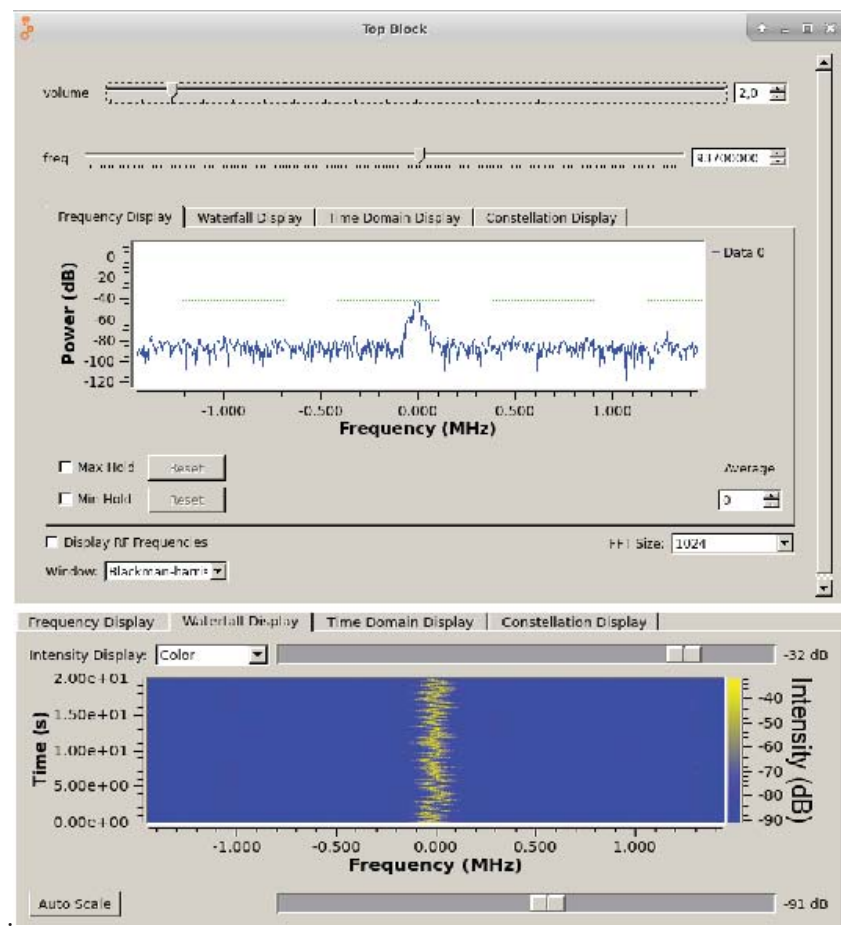

Fig. 4. Spectrographic and waterfall of WBFM Receiver.

\section{CONCLUSION}

SDR technology has many applications in radio environments and is becoming increasingly popular among all type of users. The versatility of SDR allows it to be built flexible receivers covering the extended FM band from 76 to 107.9 $\mathrm{MHz}$ and meet the demand for new equipment for the migration of AM stations to FM. Thus the user himself, with a low-cost SDR receiver can program simply WBFM your receiving system. The level of customization will adjust the gain, filter, bandwidth, and other radio frequency characteristics so as to make the system more robust.

\section{ACKNOWLEDGMENT}

The author would like to thank Telecommunications
Engineering from the IFSC - Instituto Federal de Santa Catarina, campus São José for their support in the preparation of this work.

\section{REFERENCES}

[1] Presidência da República $(2013,11)$. Decreto no 8139, Brasil [Web]. Available: http://www.planalto.gov.br/ccivil 03/ ato20112014/2013/decreto/d8139.htm

[2] Anatel (1999,03). Resolução no 116, Brasil [Web]. Available: http://www.anatel.gov.br/legislacao/resolucoes/14-1999/290resolucao-116

[3] Ministério das Comunicações $(2014,03)$. Portaria no 6467/2015/SEIMC [Web]. Available: http://www.abert.org.br/web/images/Portaria 6467 2015.pdf

[4] Portal Brasil $(2015,09)$. Migração de rádios AM para FM. Available http://www.brasil.gov.br/infraestrutura/2015/09/migracao-de-radiosam-para-fm-comeca-em-novembro

[5] Anatel (2010, 03). A Extensão da Faixa de FM (eFM) e a Migração da Faixa de OM. Available: http://www.anatel.gov.br/Portal/verificaDocumentos/documento.asp? numeroPublicacao $=244137$

[6] L. Garcia, "Introduction to the Software-defined Radio Approach", IEEE Communications Surveys \& Tutorials, vol. 10, pp. 1156-1161, Apr, 2012.

[7] R. Machado; A. M. Wyglinski, "Software Defined Radio: Bridging the Analog-Digital Divide", Proceedings of the IEEE, vol 103, pp. 409423, 2015.

[8] R. C. Reinhart; S. K. Johnson; T. J. Kacpura; C. S. Hall; C. R. Smith; J. Liebetreu, "Open Architecture Standard for NASA's SoftwareDefined Space Telecommunications Radio System", IEEE Journals \& Magazine, vol. 95, pp. 1986-1993, 2007.

[9] G. Baldini; T. Sturman; A. R. Biswas; R. Leschhorn; G. Godor; M. Street, " Security Aspects in Software Defined Radio and Cognitive Radio Networks: A Survey and A Way Ahead", IEEE Communications Surveys \& Tutorials, vol. 14, pp. 355-379, 2012

[10] P. Ferrari, "New Architecture for a Wireless Smart Sensor Based on Software-Defined Radio", Instrumentation and Measurement, IEEE Transactions, vol. 6, pp. 2133-2141, Apr, 2011.

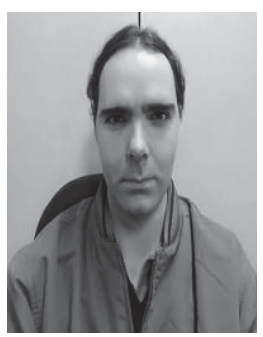

Ramon Mayor Martins was born in Paraisópolis, Minas Gerais in 1982. M.Sc in Telecommunications by the Instituto Nacional de Telecomunicações, PgC Specialist in Telecommunications Systems and B.Eng with emphasis in Telematic. He worked as a researcher at the Inatel Competence Center with embedded and RF system. Currently holds the position of Professor at Telecommunications Engineering in the Instituto Federal de Santa Catarina. He has developed research in areas like: RF systems, antennas project, satellite communications and artificial intelligence.
Cite this article:

Martins, Ramon Mayor; 2016. SDR-WBFM Receiver as an alternative to replace equipment in FM extended. SET INTERNATIONAL JOURNAL OF BROADCAST ENGINEERING. ISSN Print: 2446-9246 ISSN Online: 2446-9432. doi: 10.18580/ setijbe.2016.8. Web Link: http://dx.doi.org/10.18580/setijbe.2016.8 